He Yang, Minggao Tang*, Qiang Xu*, Zhengfeng Gong, Xiaolin Fu, Andres Alonso-Rodriguez, Huajin Li, and Yangjian Cao

\title{
Characteristics and hysteresis of saturated-unsaturated seepage of soil landslides in the Three Gorges Reservoir Area, China
}

https://doi.org/10.1515/geo-2019-0024

Received December 13, 2018; accepted March 11, 2019

\section{Introduction}

The Three Gorges Dam is the largest water conservancy project in the world. It consists of a reservoir with a capacity of 39.3 billion $\mathrm{m}^{3}$ impounding a lake $667 \mathrm{~km}$ long within the Yangtze River. The Three Gorges Reservoir Area covers 20 counties; some of them include: Zigui, Badong, Wushan, Fengjie, Yunyang, and Wanzhou (Figure 1). The project's high water is 175 m.a.s.l. (Above Sea Level) and the total length of the main streams and tributaries is almost $5500 \mathrm{~km}$. The dams impounding was effectuated in three stages. The first stage started in 2003 and finished after reaching a level of 138 m.a.s.l. Filling resumed in 2006 until reaching a threshold of 156 m.a.s.l. Finally, after the 2008 flooding season, the target maximum level was reached in 2010. Water level oscillates between 175 and 145 m.a.s.l. in operational conditions [1].

Landslides are common within Three Gorges. So far 4664 events have been recorded; 2619 of them are wading landslides [2, 3]. Particularly, 674 occurred after 2003, including eight collapses that reached the river $[4,5]$. Several assessments concluded that these eight landslides were a direct consequence of changes in the reservoir level. This is due to variations in the seepage fields on both banks. Likewise, seepage is also controlled by saturated and unsaturated permeability of soil landslides. Thus, water-soil interaction is a key feature enhancing soil landslide susceptibility. From a general perspective it is driven by two

*Corresponding Author: Qiang Xu: State Key Laboratory of Geohazard Prevention and Geoenvironment Protection, Chengdu University of Technology, Chengdu, 610059, China, E-mail: xq@cdut.edu.cn

He Yang, Zhengfeng Gong, Andres Alonso-Rodriguez, Huajin Li, Yangjian Cao: State Key Laboratory of Geohazard Prevention and Geoenvironment Protection, Chengdu University of Technology, Chengdu, 610059, China

Xiaolin Fu: Wuhan Geological Survey Center, China Geological Survey, Wuhan, 430205, China

\footnotetext{
^Corresponding Author: Minggao Tang: State Key Laboratory of Geohazard Prevention and Geoenvironment Protection, Chengdu University of Technology, Chengdu, 610059, China, E-mail: tomyr2008@163.com
} 


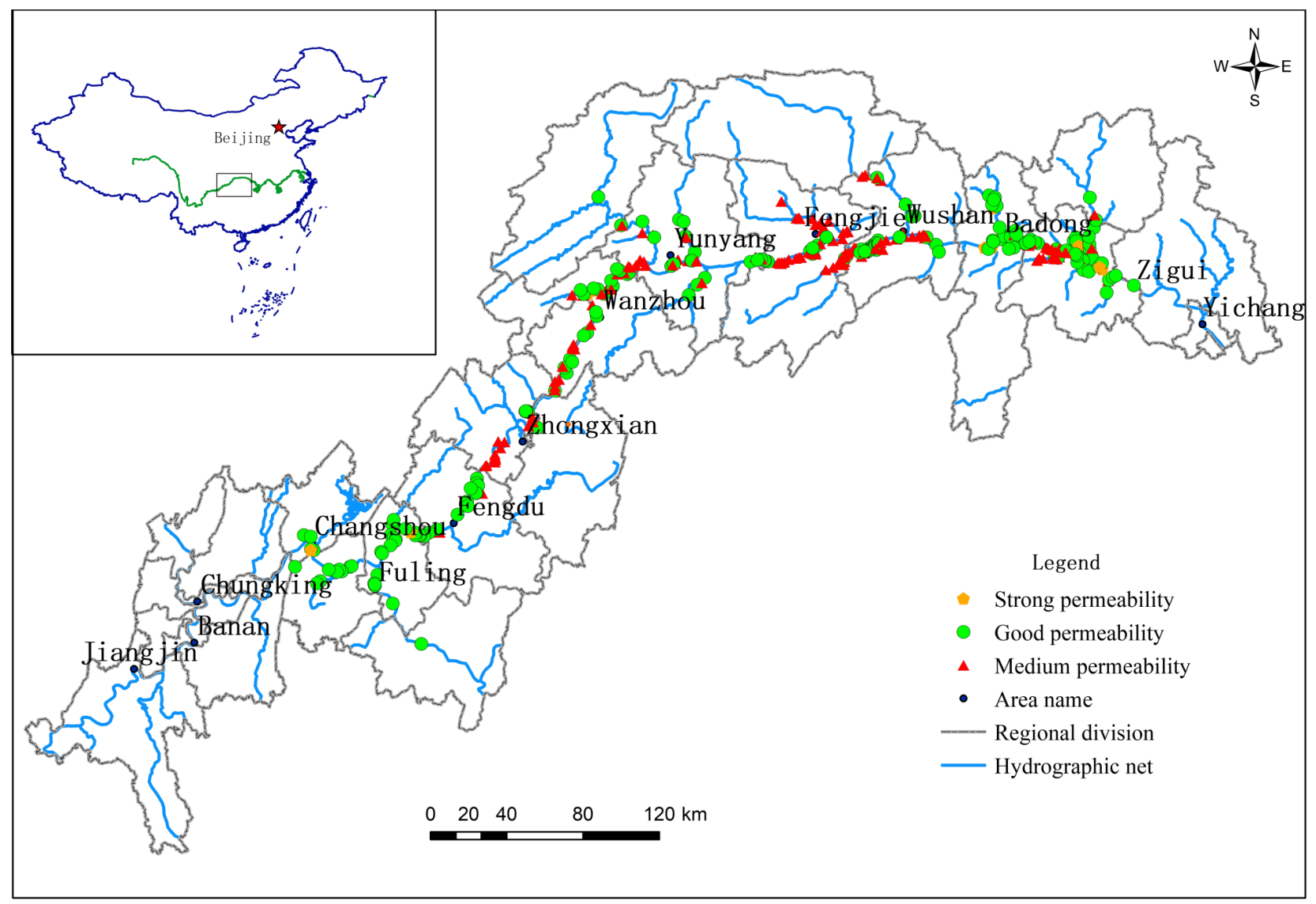

Figure 1: General view of the study area, distribution and permeability level of tested soil landslide in the Three Gorges Reservoir Area.

phenomena: 1) rainfall and water-level oscillation leads to soaking $[6,7]$ and 2) water-flow within slopes changes its effective stress state. Identification of these phenomena on diverse geological contexts allows for classification of landslides within Three Gorges into the following categories: rainfall type, soak softening type, dynamic water pressure type, floating type, and composite type [8].

The level of the lake has been close to its maximum during the past 7 years (2010-2017). Therefore, the effects of soaking are secondary. Consequently, seepage is mostly driven by short-term water level fluctuations. This has led to the following research: Liu's team [9] statistically characterized 65 permeability parameters of soil landslides in the Chongqing section of the Three Gorges Reservoir Area. Jian and his collaborators [10] conducted long-term field monitoring of the matric suction of silty clay with gravel. Ding and his team [11] conducted an indoor test study on unsaturated residual soil. Tang's group [12] studied the changing process of the in-site matric suction and the change of pore water pressure due to rainfall in several landslides within the Three Gorges Reservoir Area. Yang [13] and Ren [14] conducted a preliminary analysis of the change of the seepage field under the change of reservoir water level using the unsaturated permeability curves of three kinds of soil. Sun and his collaborators [15] proposed a simple calculation method for estimating the seepage line of slopes in the Three Gorges Reservoir Area. Huang and his team [16] analyzed the seepage stability of several landslides in the Three Gorges Reservoir Area considering different saturated permeability coefficients. Through landslide monitoring and analysis, Yi's team [17] classified the landslide time deformation patterns in the Three Gorges Reservoir Area into four types: water-storage lag, water storage synchronization, hysteresis lagging, and water withdrawal synchronization. Yi and his collaborators [18] presented the idea of hysteresis in landslides within the Three Gorges Project by studying how deformation increases after a delay of 5 to 10 days from variations in the reservoir level. They proposed that the effects of rainfall and reservoir water level on landslide deformation showcases a "hysteresis effect" and that the lag period was generally five to ten days. There are many factors that affect seepage hysteresis. The following are the most relevant: the saturated permeability coefficient of the landslide, the unsaturated permeability parameter of the landslide, the rate of change of water level in the reservoir, the 
seepage length path within the landslide, and the shape of the slope surface.

The following drawbacks have been observed: first, data on the permeability coefficient is sparse, which does not allow for a reliable description of the saturated permeability characteristics of soil landslides within the Three Gorges Reservoir Area; second, prevailing approaches use empirical methods that use expressions for materials noticeably different from what is observed within Three Gorges; third, parametric studies have been done individually, which does not allow for interaction between different conditions. Furthermore, a framework to distinguish between synchronous landslides that don't display seepage delay and hysteretic ones that present it, is yet undefined.

Therefore, in this study, we first compiled a comprehensive dataset summarizing saturated permeability characteristics of a large number of soil landslides in the Three Gorges Reservoir Area. Afterwards, we supplemented existing information by effectuating further testing on soilrock mixtures in the laboratory while performing numerical simulations to accurately analyze the seepage and hysteresis characteristics of soil landslides within the Three Gorges Reservoir.

\section{Methods}

We followed the approach outlined in Figure 2. It is comprised of the following stages:

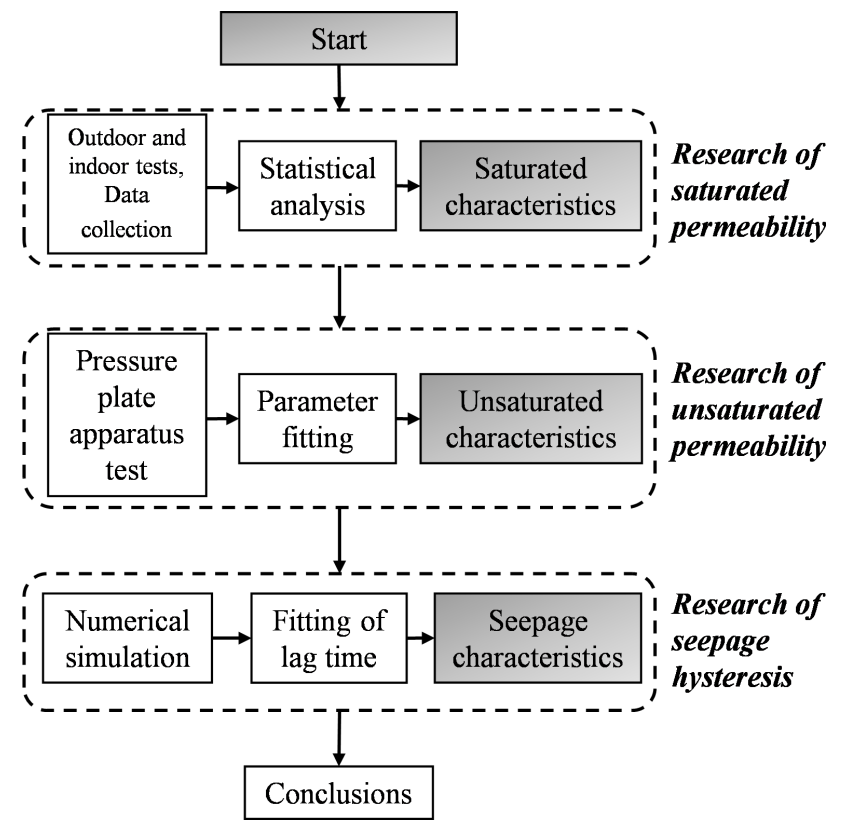

Figure 2: The workflow of the research methods

\subsection{Test of saturated permeability coefficient}

We sourced data regarding 396 soil landslides in the Three Gorges reservoir area from previous studies $[19,20]$ (Figure 1). After homogenizing results, we carried on further laboratory and field testing considering 3 sites within it, showcasing landslides where the water level is known to experience large variations. The following tests were considered: ring infiltration, water injection after drilling, forced pumping, and laboratory water penetration. Most of the tests carried out in this study are double-ring permeation tests. Further testing was performed following the guidelines of the code of water injection test for water resources and hydropower engineering of the Ministry of water resources of the People's Republic of China [21]. We performed site double loop infiltration tests in 86 soil landslides. Eventually, we compiled a database with results of 1188 field and laboratory water penetration tests from 396 soil landslides within Three Gorges Reservoir Area. The permeability data was classified following guidelines of the Engineering Geology Manual of China's Geological Survey [22], and conventional statistical assessments were done for each category. Overall landslide permeability was defined using an average of several samples within it.

\subsection{Research of unsaturated soil-water characteristic parameter}

Variation of water level induces cycles of drying and wetting in landslides, leading to cycles of unsaturated and saturated soils. The two major hydraulic characteristics of unsaturated soils are the soil-water characteristic curve (SWCC), and the permeability coefficient function [23]. Consequently, it is possible to obtain the later from the former. Therefore, we focused on assessing the soil-water characteristic parameters as a way to determine the unsaturated soil properties of inquired landslides.

The unsaturated permeability was assessed through the full suction double-cell extractor for SDSWCC tests developed by Earth Products China Ltd [24]. Most (98\%) of assessed soil landslides were comprised of rock-soil mixtures. Landslides with gravel content above $20 \%$ are more than $85 \%$ of the total amount. Field measurements of rocksoil matrix suction were found to be low.

Our field measurements showed that suction by landslides bodies comprised mostly of soil is commonly less than $100 \mathrm{kPa}$. Consequently, we defined the soil water characteristics (SWCC) considering a suction range between 0 and $200 \mathrm{kPa}$. Effects of gravel within landslides 
bodies were assessed by performing laboratory tests on specimens where gravel content reached $50 \%$, judged representative of what is observed in Three Gorges. Control specimens were elaborated considering gravel content ratios of 30 and $60 \%$. Effects of material gradation were incorporated in our analyses by performing tests on samples with sparse and continuous granulometric curves. Constraints in our equipment imposed by the size of the ring knife available in our laboratory required enforcement of a maximum particle size $20 \mathrm{~mm}$. A value of $2 \mathrm{~mm}$ was set as the lower limit as it is the threshold separating gravel and sand. Gradation was defined in the following bins: 2$5 \mathrm{~mm}, 5-10 \mathrm{~mm}, 10-20 \mathrm{~mm}$, and 2-20 mm as shown in Figure 3. Fine content was characterized by its plasticity index (Ip). Soils within studied landslides are mostly comprised of silty clay with an Ip $=11$. Control samples were evaluated considering an Ip $=15$. Samples with representative void ratios were evaluated by achieving a dry density of $1.8 \mathrm{~g} \cdot \mathrm{cm}^{-3}$, while a value of $2.0 \mathrm{~g} \cdot \mathrm{cm}^{-3}$ was set as a target for control specimens. Samples consisted of a mixture of silty clay and lime-gray limestone gravel. Further details about specific testing procedures are in [25]. The combination of all inquired parameters led to the definition of eight sample categories (Table 1).

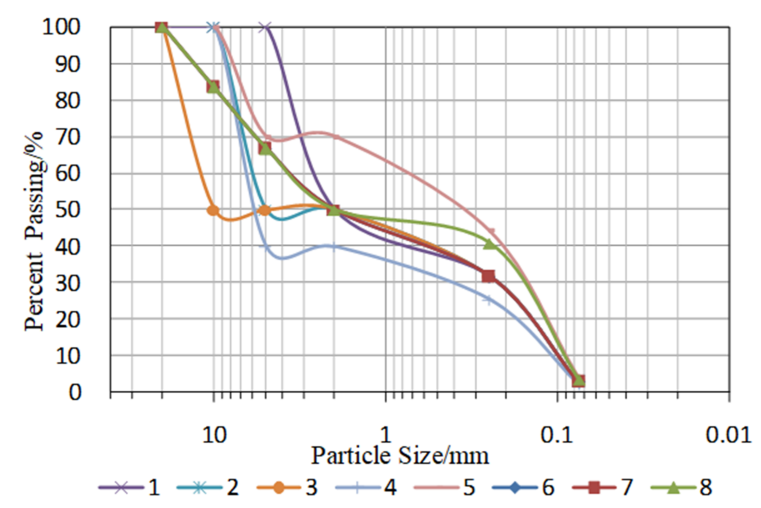

Figure 3: Granulometric curves

\subsection{Analysis of the seepage hysteresis}

The seepage hysteresis of a landslide enhances both as the rate of reservoir water level change increases and the seepage path becomes longer, and decreases if the saturated permeability coefficient increases and slope becomes steeper. There is feedback between the saturated permeability coefficient and the variation of water level in the reservoir. If the saturated permeability coefficient of
Table 1: Test scheme

\begin{tabular}{|c|c|c|c|c|c|}
\hline $\begin{array}{c}\text { Number of } \\
\text { sample }\end{array}$ & $\begin{array}{l}\text { Particle } \\
\text { size }(\mathrm{mm})\end{array}$ & $\begin{array}{l}\text { Content of } \\
\text { gravel (\%) }\end{array}$ & $\begin{array}{l}\text { Dry density } \\
\rho_{d}\left(g^{\circ} \mathrm{cm}^{-3}\right)\end{array}$ & $\begin{array}{c}\text { Plasticity } \\
\text { index } \\
\text { Ip }\end{array}$ & Description \\
\hline s1 & $2 \sim 5$ & 50 & 1.80 & 11 & The content of gravel \\
\hline s2 & $5 \sim 10$ & 50 & 1.80 & 11 & remains unchanged. \\
\hline s3 & $10 \sim 20$ & 50 & 1.80 & 11 & Change in particle size \\
\hline$s 4$ & $5 \sim 10$ & 60 & 1.80 & 11 & $\begin{array}{c}\text { The particle size remains } \\
\text { unchanged }\end{array}$ \\
\hline 55 & $5-10$ & 30 & 1.80 & 11 & Change in content of gravel \\
\hline 56 & $2 \sim 20$ & 50 & 1.80 & 11 & Continuous gravel grading, \\
\hline s7 & $2 \sim 20$ & 50 & 2.0 & 11 & $\begin{array}{l}\text { Different dry density } \\
\text { Continuous gravel grading, }\end{array}$ \\
\hline 58 & $2 \sim 20$ & 50 & 1.80 & 15 & $\begin{array}{l}\text { Soil plasticity index } \\
\text { increases }\end{array}$ \\
\hline
\end{tabular}

the landslide is small and the rate of water level change also is low; seepage hysteresis will be weak and seepage synchronization may occur. Even, if the saturated permeability coefficient is large, when the reservoir water level rises and falls quickly, seepage flow may become hysteretic. Therefore, a comprehensive analysis was performed using the ratio $\mathrm{h}=k / \Delta \mathrm{V}$ as the index of the hysteresis coefficient. $k$ represents the saturated permeability coefficient of the landslide body and $\Delta \mathrm{V}$ represents the rate of change of the reservoir water level. Likewise, the seepage path is conditioned by the slope of the surface on which water level oscillates. The seepage path will reduce as it increases. In our work, we focus on assessing $\mathrm{h}$ considering slope and seepage path as secondary factors.

The relationship between reservoir water level fluctuation and the hysteresis nature of landslides in the Three Gorges Reservoir area was investigated by constructing a model in Geo-seep. Landslide bodies were represented as niform soil-rock mixtures sliding on bedrock, according to the generalized geological profile displayed in Figure 4. In overall terms, hysteresis caused by the rise of the reservoir water level is beneficial to the stability of the landslide, while water level decline induces hydrodynamic pressure variations that can render slopes unstable. As our interest is on the most adverse conditions, we only performed tests where water level fell.

(1) Model definition

Three basic arrangements (Figure 6) were considered for analyzing the effects of the seepage path on hysteresis. Several thicknesses and slopes of the landslide body were also assessed, leading to three basic models. Model 1 has a seepage path of $74 \mathrm{~m}$ within the landslide body and a slope of $24^{\circ}$. The seepage path of Model 2 is $49 \mathrm{~m}$ within the landslide body and a slope of $24^{\circ}$. Model 3 has a seepage path of $74 \mathrm{~m}$ within the landslide body and a slope of $19^{\circ}$. Computations were performed in Geo-studio, a two-dimensional 


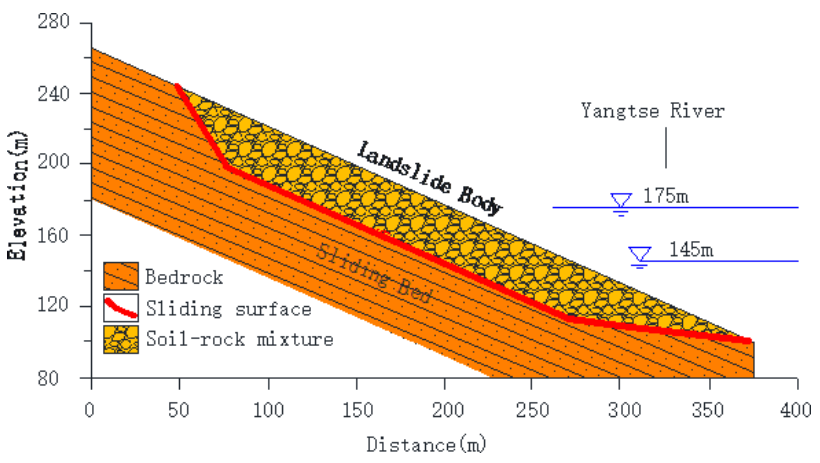

Figure 4: Generalized geological profile of soil landslide

finite element numerical simulation software, "seep/w." The mesh grill was defined automatically by the employed software, considering $3 \mathrm{~m}$ long elements.

(2) Parameters

1) Permeability parameters of landslide body

In addition to the saturated permeability coefficient, the seepage numerical analysis also involves the SWCC and the unsaturated permeability coefficient function. The latter are the most important parameters for describing the unsaturated seepage characteristics of the soil. There is a clear relationship between saturated permeability coefficients and unsaturated permeability parameters, so changes can't be imposed independently. The boundary of the saturated permeability coefficient and characteristic coefficient values were selected as the calculation parameters of the landslide bodies based on both statistical properties of the saturated permeability coefficients of the soil landslides in the Three Gorges Reservoir Area and on the classification of the infiltration grade of the landslide bodies (Table 2). According to the saturated permeability coefficient and the values in Table 6 , the parameter values of SWCC were selected (Table 2). The SWCC was calculated using the Fredlund-Xing parameter formula [26]. The unsaturated soil-water characteristic parameters were set based on variations of nominal parameters using the saturated permeability coefficient. The permeability coefficient function was calculated from the SWCC using the empirical formula provided by Geo-seep [27].

2) Permeability parameters of the sliding bed

As the study area is mainly located in the water level fluctuation zone, characteristics of the sliding bed are secondary. A representative value of $k=0.0015 \mathrm{~m} / \mathrm{d}$ was adopted, leading to the unsaturated permeability curve depicted in Figure 5.

(3) Conditions and process

Two different water level stages were considered in our assessments, for both numerical simulations and as target real-time scenarios to be replicated at small-scale in the
Table 2: Parameters of numerical simulation analyses

\begin{tabular}{|c|c|c|c|c|c|c|}
\hline \multirow{2}{*}{ Number } & \multirow{2}{*}{\multicolumn{2}{|c|}{$\begin{array}{l}\text { Saturated permeability } \\
\text { coefficient }(m / d)\end{array}$}} & \multicolumn{4}{|c|}{ Unsaturated parameters } \\
\hline & & & $a(\mathrm{kPa})$ & $n$ & $m$ & $\begin{array}{c}\theta s \\
\left(\mathrm{~m}^{3} / \mathrm{m}^{3}\right)\end{array}$ \\
\hline 1 & Maximum value & 21 & 3.516 & 0.561 & 1.065 & 0.279 \\
\hline 2 & Threshold value & 10 & 3.985 & 0.439 & 1.083 & 0.298 \\
\hline 3 & $\begin{array}{c}\text { Characteristic } \\
\text { value }\end{array}$ & 5 & 9.372 & 0.403 & 1.283 & 0.308 \\
\hline 4 & $\begin{array}{c}\text { Characteristic } \\
\text { value }\end{array}$ & $\begin{array}{c}2 . \\
4\end{array}$ & 10.319 & 0.392 & 1.356 & 0.32 \\
\hline 5 & Limit value & 1 & 11.319 & 0.382 & 1.456 & 0.358 \\
\hline
\end{tabular}

Table 3: Conditions of seepage flow calculation

\begin{tabular}{ccccc}
\hline Number & $\begin{array}{c}\text { Content of } \\
\text { calculation } \\
\text { conditions }\end{array}$ & $\begin{array}{c}\text { Water level } \\
\text { drop rate } \\
(\mathrm{m} / \mathrm{d})\end{array}$ & $\begin{array}{c}\text { Content of } \\
\text { calculation } \\
\text { conditions }\end{array}$ & $\begin{array}{c}\text { Water level drop } \\
\text { rate }(\mathrm{m} / \mathrm{d})\end{array}$ \\
\hline 1 & $\begin{array}{c}175 \mathrm{~m} \\
\text { continuously }\end{array}$ & 0.114 & $\begin{array}{c}159 \mathrm{~m} \\
\text { continuously } \\
\text { dropped to } 145\end{array}$ & 0.6 \\
2 & $\begin{array}{c}\mathrm{m} \\
\text { dropped to } 159 \mathrm{~m}\end{array}$ & & 1.2 \\
\hline
\end{tabular}

laboratory. First, a decrease of $0.114 \mathrm{~m} / \mathrm{d}$ was enforced, following operational conditions of the Three Gorges Reservoir. This rate of decline was maintained until reaching a level of 159 m.a.s.l. In addition, the following decrease ratios were investigated: $0.6,1.2$, and $2.0 \mathrm{~m} / \mathrm{d}$. Once a reservoir level of 145 m.a.s.l. was reached, it was kept constant for 200 to 300 days. The water level at the posterior border of the landslide was set to a fixed value of 220 m.a.s.l. Thus, three diverse scenarios were defined (Table 3).

\section{Results}

\subsection{Saturated permeability characteristics of soil landslides}

Sourced data collected within this study show that the maximum permeability coefficient ranges between $21 \mathrm{~m} / \mathrm{d}$, and $0.01 \mathrm{~m} / \mathrm{d}$ (Table 4). Figure 7 shows the distribution of the permeability level of soil landslides. $3 \%$ of wading landslides on the bank of the Yangtze River showcase values of $\mathrm{k}>10$ (strong permeability). 51\% have permeability values that range between 1 and 10 (good). The last column, $46 \%$ display permeability values of $\mathrm{k}$ between 0.01 and 1 (medium). Thus, the permeability of soil land- 


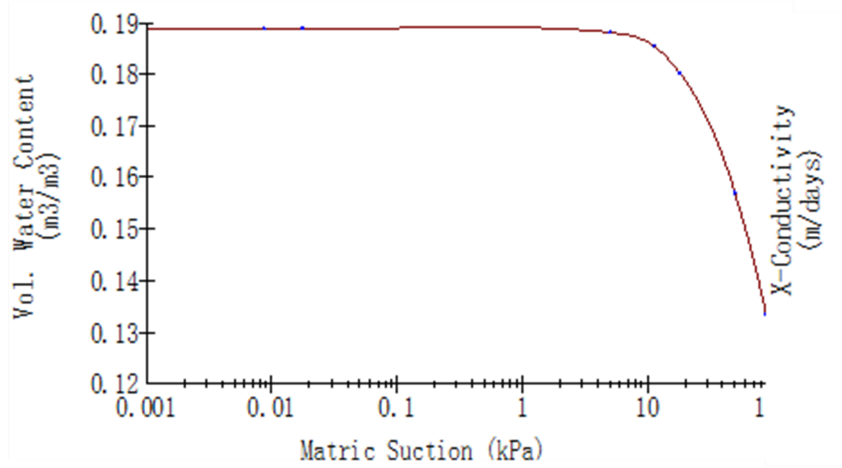

b

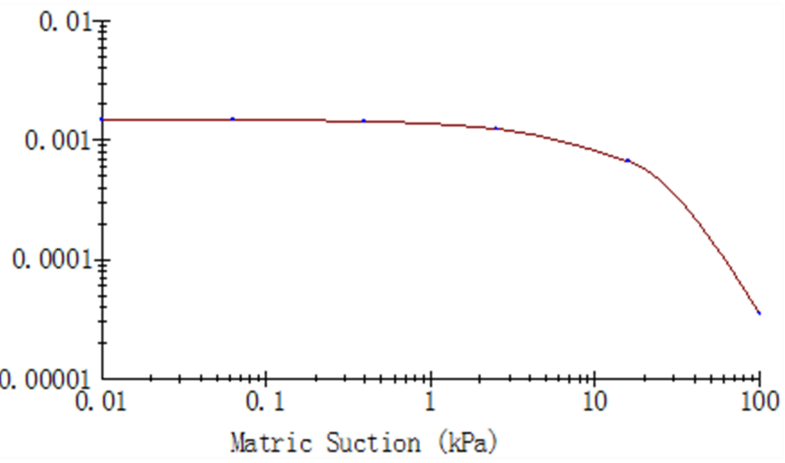

Figure 5: Unsaturated permeability curve. (a) Soil-water characteristic curve, (b) Permeability function curve
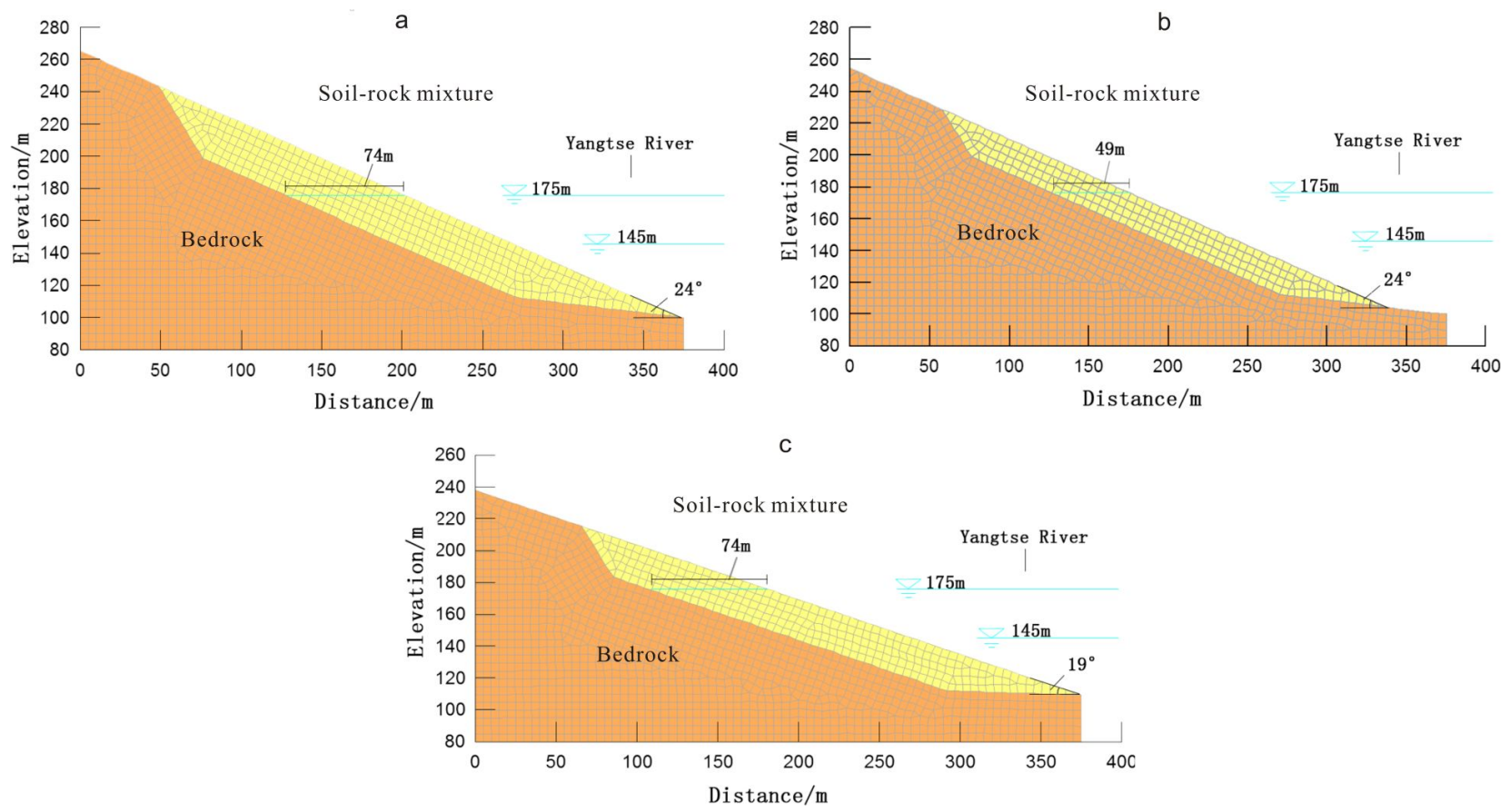

Figure 6: Calculation numerical model: (a) Model 1, (b) Model 2, (c) Model 3

slides in the Three Gorges Reservoir area is mainly good and moderate; Figure 8 shows the spatial distribution of assessed soil landslides. Medium permeability bodies are clustered in the Fengjie, Wuxi, and Zhongxian locations.

\subsection{Unsaturated permeability characteristics of soil landslides}

\subsubsection{The soil-water characteristic curve}

Through tests of the pressure plate instrument, the SWCC of the de-wetting process of the eight types of samples were obtained (Table 5 and Figure 9). The SWCC of several types
Table 4: Statistical characteristics of permeability coefficient

\begin{tabular}{|c|c|c|c|}
\hline $\begin{array}{c}\text { Statistical } \\
\text { characteristi } \\
\text { cs }\end{array}$ & $\begin{array}{l}\text { Characteristi } \\
\text { c value }(\mathrm{m} / \mathrm{d})\end{array}$ & $\begin{array}{c}\text { Statistical } \\
\text { characteristi } \\
\text { cs }\end{array}$ & $\begin{array}{l}\text { Characteristi } \\
\text { c value }(\mathrm{m} / \mathrm{d})\end{array}$ \\
\hline Maximum & 21.00 & Median & 1.30 \\
\hline Minimum & 0.013 & Mode & 2.50 \\
\hline Average & 2.32 & $\begin{array}{l}\text { Standard } \\
\text { deviation }\end{array}$ & 3.04 \\
\hline
\end{tabular}




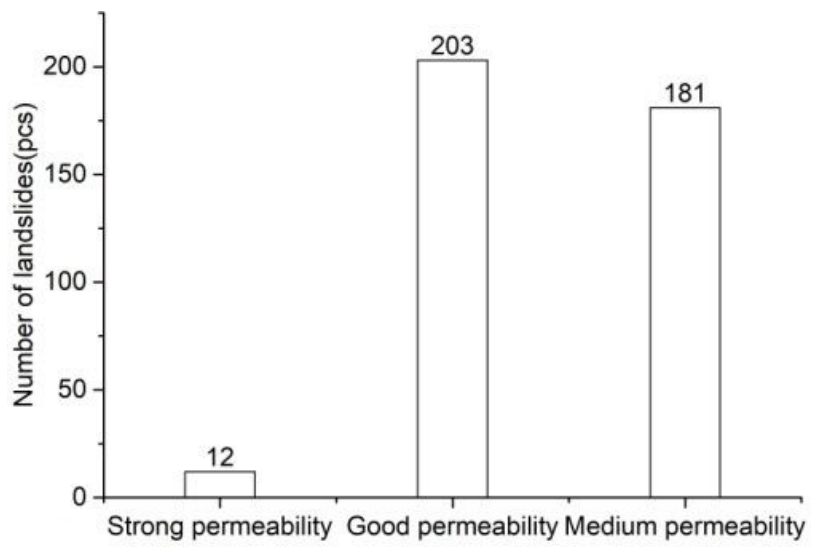

Figure 7: Distribution of permeability level of soil landslides in Three Gorges Reservoir Area

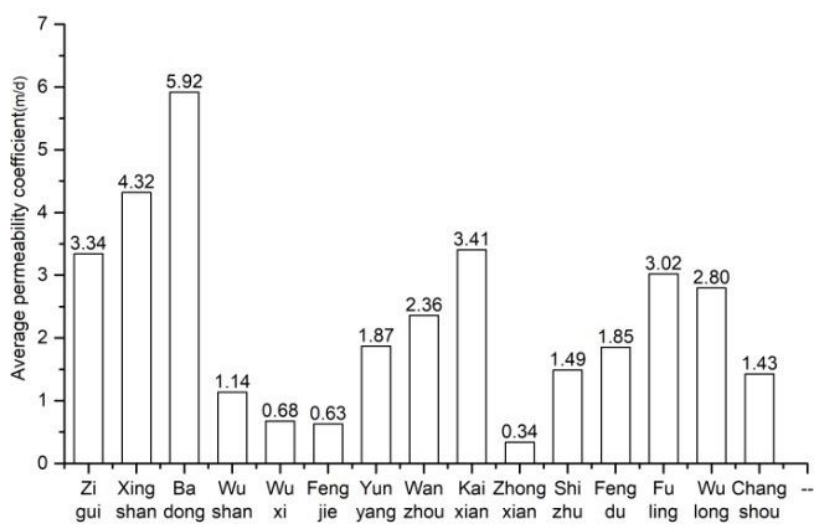

Figure 8: Regional distribution of average permeability coefficient of soil landslides in Three Gorges Reservoir Area.

of soil-rock mixture shows that the de-wetting path first drops steeply, however, as the matrix suction increases, the curve gradually becomes flat (Figure 9). The first observed trend is explained by the removal of water from large discontinuities and pores. In contrast, the first section of the SWCC curves of conventional soils are relatively gentle, following trends usually observed for clay and silty clay.

The shape of the SWCC is slightly conditioned by the average particle size of gravel (Figure 9a) while being insensitive to its gradation (Figure 9b). As seen in Figure 9b, as the gravel content in the sample increases, the saturated water content gradually decreases; under the same matrix suction, the moisture content also decreased accordingly, and the degree of reduction was positively correlated with the gravel content; if water content is kept constant, matric suction increases as the gravel content decreases. The shape of the SWCC is moderately affected by dry-density (Figure 9c). As the dry density of the sample increases, the saturated moisture content decreases, Thus, the water- holding capacity becomes gradually larger. Eventually, both curves will cross after the matric suction reaches $200 \mathrm{kPa}$. The curve with a smaller dry density is gentler. The parameter that most affects SWCC is $I_{p}$ (Figure 9d). As $I_{p}$ increases, the saturated water content augments, making the slope of the SWCC gentler; therefore, the matrix suction force becomes larger if the water content is fixed $[28,29]$. We found that the saturated water content of continuously graded samples was relatively small compared to the control case. When matrix suction is small (less than $20 \mathrm{kPa}$ ), water content changes slowly; when the matrix suction is large (more than $20 \mathrm{kPa}$ ), the water content changes quickly.

\subsubsection{Fitting analysis of unsaturated permeability parameters}

With the development of unsaturated soil mechanics, a large number of models have been proposed. Among them the power function form of the logarithmic function, the power function form, the fractal model, the logarithmic function form, and the mathematical model of the general expression [30]; according to the number of parameters, it can be divided into two-parametered, threeparametered, and four-parametered in the mathematical model [31]. We selected the Fredlund-Xing three-parameter model (FX3) [32] to describe the relationship between saturated and overall moisture content and the rock-soil matrix suction. The FX3 model is widely used because it has a relatively low number of parameters and is easy to use. It is described by the functional form presented in equation (1):

$$
\theta=\frac{\theta_{s}}{\left\{\ln \left[e+\left(\frac{\psi}{a}\right)^{n}\right]\right\}^{m}}
$$

Where $\theta$ is the volumetric moisture content; $\theta_{s}$ is the saturated volumetric moisture content; $\Psi$ is the soil matrix suction; $a, n$ and $m$ are the fitting parameters; where $a$ is related to the air intake value, $n$ is the pore size distribution coefficient of the soil, and $m$ is the parameter related to the residual moisture content [26].

The definition of parameters based on data obtained in our study was done by considering the Gauss-Newton non-linear least squares fitting algorithm implemented in Matlab $\odot$ [33]. Results are presented in Figure 10 and Table 6.

Considering all studied rock-soil mixtures, we found that the $a$ value increases gradually as the average size of gravel particles becomes larger, the relative content of gravel diminishes, dry density is larger, and the Ip of the 


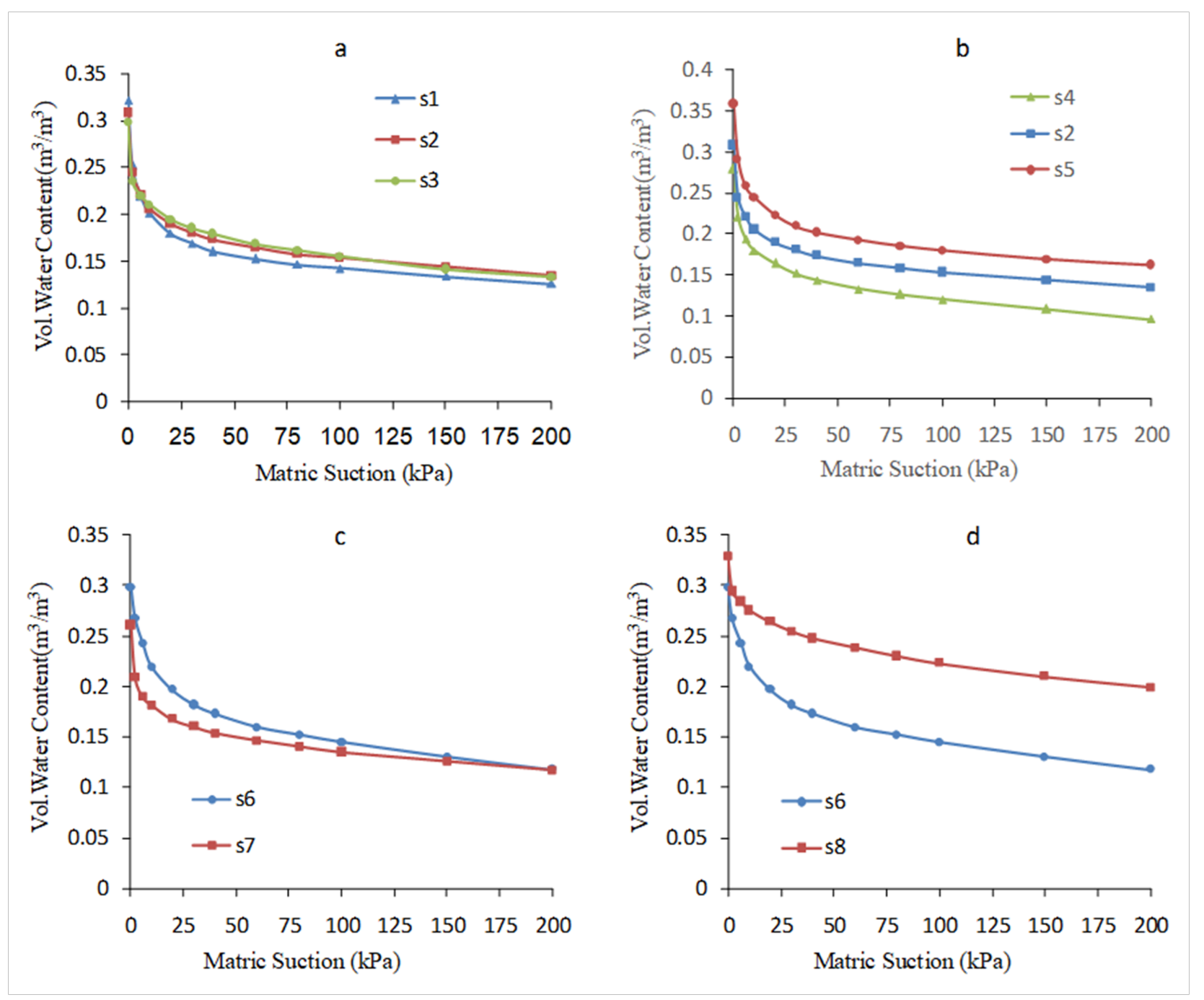

Figure 9: Soil-water characteristic curve of the desiccant path of the sample:(a) Gravel content is $50 \%$, particle size is different, (b) Gravel size is 5-10 mm, gravel content is different, (c) Continuous gravel grading, content is 50\%; different dry density, (d) Continuous gravel grading, content is $50 \%$; different plasticity index of soil

Table 5: Test data of soil-water characteristics

\begin{tabular}{|c|c|c|c|c|c|c|c|c|c|c|c|c|c|}
\hline Matrix suction(K & & 0 & 2 & 6 & 10 & 20 & 30 & 40 & 60 & 80 & 100 & 150 & 200 \\
\hline \multirow{8}{*}{$\begin{array}{c}\text { volumetric } \\
\text { water content } \\
\qquad\left(\mathrm{m}^{3} / \mathrm{m}^{3}\right)\end{array}$} & s1 & 0.321 & 0.252 & 0.219 & 0.201 & 0.180 & 0.169 & 0.160 & 0.152 & 0.147 & 0.143 & 0.134 & 0.126 \\
\hline & s2 & 0.308 & 0.245 & 0.221 & 0.205 & 0.190 & 0.181 & 0.173 & 0.165 & 0.158 & 0.153 & 0.144 & 0.134 \\
\hline & s3 & 0.298 & 0.235 & 0.220 & 0.210 & 0.195 & 0.186 & 0.180 & 0.169 & 0.162 & 0.155 & 0.141 & 0.133 \\
\hline & s4 & 0.279 & 0.221 & 0.194 & 0.180 & 0.164 & 0.152 & 0.144 & 0.133 & 0.126 & 0.120 & 0.108 & 0.960 \\
\hline & s5 & 0.358 & 0.291 & 0.258 & 0.244 & 0.223 & 0.210 & 0.202 & 0.192 & 0.185 & 0.180 & 0.169 & 0.162 \\
\hline & s6 & 0.298 & 0.267 & 0.243 & 0.219 & 0.197 & 0.182 & 0.173 & 0.160 & 0.152 & 0.145 & 0.131 & 0.118 \\
\hline & s7 & 0.261 & 0.209 & 0.190 & 0.181 & 0.168 & 0.160 & 0.154 & 0.147 & 0.140 & 0.135 & 0.126 & 0.117 \\
\hline & s8 & 0.329 & 0.294 & 0.284 & 0.275 & 0.264 & 0.255 & 0.248 & 0.238 & 0.230 & 0.223 & 0.210 & 0.199 \\
\hline
\end{tabular}


Table 6: Model fitting parameters; values and relevance

\begin{tabular}{ccccc}
\hline $\begin{array}{c}\text { Number } \\
\text { of sample }\end{array}$ & $a(\mathrm{kPa})$ & $n$ & $m$ & relevance \\
\hline s1 & 1.371 & 0.684 & 0.734 & 0.999 \\
s2 & 3.985 & 0.439 & 1.083 & 0.998 \\
s3 & 9.372 & 0.403 & 1.283 & 0.995 \\
s4 & 3.516 & 0.561 & 1.065 & 0.985 \\
s5 & 11.319 & 0.382 & 1.456 & 0.983 \\
s6 & 8.197 & 0.718 & 0.959 & 0.995 \\
s7 & 18.578 & 0.365 & 1.585 & 0.999 \\
s8 & 48.578 & 0.350 & 1.268 & 0.998 \\
\hline
\end{tabular}

fine matrix becomes larger. If a unitary volume of gravel soil is considered; a larger particle size will imply that the number of particles within it will be less, leading to a reduction in the effective surface of the gravel compromising air circulation, so the value of a becomes larger. Likewise, as the relative content of gravels is reduced within the same unitary volume, spaces between particles are more likely to be filled by fine grains, again leading to less air circulation and an increase in the a value. Locations with larger dry densities will likely have lower void ratios, diminishing the air penetration rate. Finally, an increase in the Ip index of the fine content of a site indicates a larger share of clay within it. This leads to better cementation of gravel particles, becoming obstacles for incoming air. All these obstacles for air-soil interaction lead to the observed increase in the value of $a$.

The value of $n$ is related to the rate of dehydration after the suction force of the matrix exceeds the intake value $a$. Particularly, it can be found after plotting the midline segment of the SWCC on a logarithmic scale. We found that among sites studied, $\mathrm{n}$ value decreases with an increase of gravel particle size, the dry density, and the plasticity index of the soil particles, and a decrease of the gravel content. Well-graded particles with different sizes will lead to improved water flow. If the particle size is too large and gradation is uniform, physical barriers can arise, constraining water outflow. A lower content of gravel implies a larger share of low-permeability silts and clays. And as stated before, higher dry densities imply that gravel particles have smaller pores, thus, showcasing lower permeability than less-dense ones. Finally, larger Ip values are associated with more low-permeability clays.

The $m$ parameter is related to the residual water content. We observed that the $m$ value becomes larger as the particle size of gravel increases in a site, gradually increases as gravel content decreases, gradually increases as
Table 7: behavior of parameters of the FX3 model

\begin{tabular}{ccccc}
\hline Parameters & $\begin{array}{c}\text { Gravel } \\
\text { particle } \\
\text { size }\end{array}$ & $\begin{array}{c}\text { Gravel } \\
\text { content }\end{array}$ & Dry density & $\begin{array}{c}\text { Plasticity } \\
\text { index }\end{array}$ \\
\hline$a$ & $\begin{array}{c}\text { Positive } \\
\text { correlation }\end{array}$ & $\begin{array}{c}\text { Negative } \\
\text { correlation }\end{array}$ & $\begin{array}{c}\text { Positive } \\
\text { correlation }\end{array}$ & $\begin{array}{c}\text { Positive } \\
\text { correlation }\end{array}$ \\
$n$ & $\begin{array}{c}\text { Negative } \\
\text { correlation }\end{array}$ & $\begin{array}{c}\text { Positive } \\
\text { correlation }\end{array}$ & $\begin{array}{c}\text { Negative } \\
\text { correlation }\end{array}$ & $\begin{array}{c}\text { Negative } \\
\text { correlation }\end{array}$ \\
& $\begin{array}{c}\text { Positive } \\
\text { correlation }\end{array}$ & $\begin{array}{c}\text { Negative } \\
\text { correlation }\end{array}$ & $\begin{array}{c}\text { Positive } \\
\text { correlation }\end{array}$ & $\begin{array}{c}\text { Positive } \\
\text { correlation }\end{array}$ \\
\hline
\end{tabular}

sites show higher dry densities, and increases as the value of $I_{p}$ of the fine fraction becomes larger. These trends are explained by the following phenomena; usually there is a direct relationship between particle size and dry density of gravels. Thus, materials with larger nominal sizes tend to be denser, and consequently, pores within them are expected to be smaller than in materials with a smaller particle size. This slows water release during desiccation. Similarly, a lower relative content of gravel indicates a larger share of less-permeable, fine-grained soil. Finally, a larger overall dry density indicates that pores have diminishing dimensions, making the release of trapped water unlikely. An increasing value of I $p$ implies a higher relative amount of hygroscopic clay. All these factors lead to residual increases in water content, explaining trends observed on the $\mathrm{m}$ parameter. Trends among all parameters are summarized in Table 7.

\subsection{Hysteresis characteristics and change law on seepage field}

\subsubsection{Hysteresis characteristics of seepage}

The relationship between lag times and hysteresis coefficients is shown in Figure 11 and Table 8 for all three models considered in this study.

Table 8 shows the different lag times for the three types of models for several hysteresis coefficients. For values of $h \geq 35$, models 1 and 2 show 0 days of lag, indicating that seepage in the landslide body and reservoir level were decreasing simultaneously. However, Model 3 has a lag time of 1 day for the same $h=35$. A comparison of results from models 2 and 1 when subjected to the same hysteresis coefficient, show that the lag time of model 2 was only slightly lower. Comparison of results indicates that 
Table 8: Hysteresis coefficient - lag time relationship

\begin{tabular}{cccc}
\hline $\begin{array}{c}\text { Hysteresis } \\
\text { coefficient }\end{array}$ & \multicolumn{3}{c}{ Lag time (day) } \\
$h$ & Model 1 & Model 2 & Model 3 \\
\hline 35.00 & 0 & 0 & 1 \\
17.50 & 2 & 2 & 5 \\
16.67 & 3 & 3 & 7 \\
10.50 & 4 & 3 & 11 \\
8.33 & 7 & 6 & 15 \\
5.00 & 8 & 7 & 16 \\
2.50 & 16 & 15 & 34 \\
2.00 & 51 & 49 & 90 \\
1.67 & 146 & 143 & 198 \\
0.83 & 158 & 148 & 223 \\
0.50 & 166 & 160 & 240 \\
\hline
\end{tabular}

percolation distance is a secondary factor as its effects are marginal. Joint review of results from models 3 and 1 show that when subjected to the same hysteresis coefficient, the lag time of the first is between 1.35 and 2.75 times larger than what is observed for the former. This shows lag time increases as landslide slope in the reservoir water level fluctuation zone decreases and vice versa. The comparison of the three models showed that the hysteresis coefficient is the main factor affecting seepage hysteresis. The critical hysteresis coefficient is not a certain value and will vary with change of the gradient of the slope in the water level fluctuation area. Therefore, the gradient of slope in the water level fluctuation area is an important factor affecting the hysteresis of the seepage flow. When the gradient of slope in water level fluctuation area is $24^{\circ}$, the critical hysteresis coefficients of the synchronous and hysteretic landslides are 35. With the decrease of the gradient of slope, the critical hysteresis coefficient increases; with the increase of the gradient of slope, the critical hysteresis coefficient decreases. Since the maximum saturated permeability coefficient of the soil landslides in the Three Gorges Reservoir Area is $21 \mathrm{~m} / \mathrm{d}$, the ratio between it and the maximum decline rate was 35 . According to the survey, the gradient of the slope in the Three Gorges Reservoir Area ranges between $15 \sim 30^{\circ}$; but, $97 \%$ of soil landslides in the Three Gorges Reservoir Area have saturated permeability coefficients less than $10 \mathrm{~m} / \mathrm{d}$. Therefore, it can be inferred that at
Table 9: Classification of hysteresis levels of landslide bodies

\begin{tabular}{lc}
\hline $\begin{array}{l}\text { Degree } \\
\text { hysteresis }\end{array}$ & of \\
\hline Strong & $\begin{array}{c}\text { Hysteresis } \\
\text { coefficient }\end{array}$ \\
Medium & $h \leqslant 1.67$ \\
Weak & $1.67<h \leqslant 2.5$ \\
& $35>h>2.5$ \\
\hline
\end{tabular}

least $90 \%$ of soil landslides in the Three Gorges Reservoir Area are of the hysteretic type, and few landslides could achieve synchronization of seepage and reservoir water level.

Figure 11 shows the variation curve of lag time with hysteresis coefficient. It can be seen that as the hysteresis coefficient increases, the lag time decreases, showing at first a steep descent, then the rate of change slows. This allows for the definition of two distinct behavioral regimes. Landslides with strong hysteresis produce large seepage pressures, which are extremely unfavorable to the stability of landslides, while the seepage pressures generated by landslides with low hysteresis are almost zero. Therefore, it is necessary to classify hysteresis predominance. If the results of Figure 11 are plotted on a logarithmic scale, Figure 12 is obtained.

Figure 12 shows the variation of the lag time with the logarithm of the hysteresis coefficient. From this figure, it can be seen that the curve can be divided into three linear segments. The first segment has a small slope; the middle segment presents a steeper slope, and the last segment is almost flat. According to the characteristics of the three segments of the curve, the hysteresis coefficients of 1.67 and 2.5 can be considered to define thresholds for limit values, allowing for definition of the following hysteresis categories: strong, medium and weak, as shown in Table 9.

\subsubsection{Lag time prediction in terms of the hysteresis parameter}

In this study, after assessing several regression models, we found than an exponential relationship between lag time and the hysteresis parameter (Equation 2) provides the best approach for assessing the dependence between 

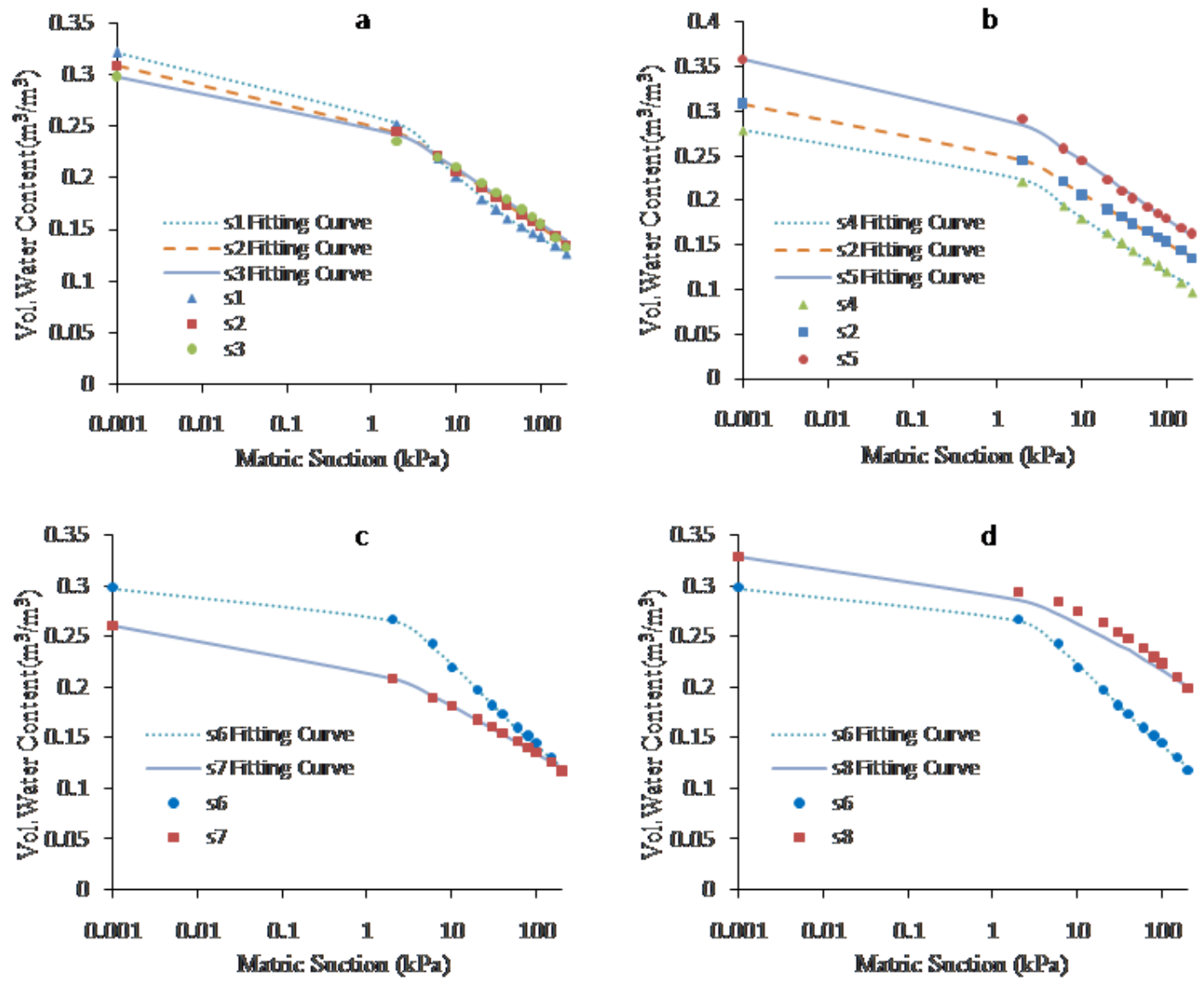

Figure 10: Soil-water characteristic curve test results and fitting curve: (a) Gravel content is $50 \%$, particle size is different, (b) Gravel size is 5-10 mm, gravel content is different, (c) Continuous gravel grading, content is $50 \%$; different dry density, (d) Continuous gravel grading, content is $50 \%$; different plasticity index of soil.

Table 10: Formula fitting parameter values and their correlation degree

\begin{tabular}{cccc}
\hline & \multicolumn{2}{c}{ Parameter } & Correlatio \\
Number & $\alpha$ & $\beta$ & $\mathrm{n}$ \\
& $\alpha$ & degree \\
\hline Model 1 & 247.653 & -0.615 & 0.885 \\
Model 2 & 236.15 & -0.611 & 0.880 \\
Model 3 & 344.674 & -0.576 & 0.916 \\
\hline
\end{tabular}

time lag and $h$.

$$
t=\alpha e^{\beta h}
$$

where $t$ is the lag time, the unit is in days; $h$ is the lag coefficient; and $\alpha, \beta$ are site dependent parameters. If the logarithm of equation (2) is taken on both sides, ordinary least-squares regression can be employed to find parameters $\alpha$ and $\beta$ based on data obtained in this study (Table 10). In practical terms, the relationship between models 1 and 2 is the same, showing how seepage phenomena is only slightly affected by distance to the free flow boundary. On the contrary, results from model 3 clearly show a different trend, indicating how the slope angle on the free boundary plays are a more critical role. Parameters $\alpha, \beta$ can be calculated through linear interpolation. 


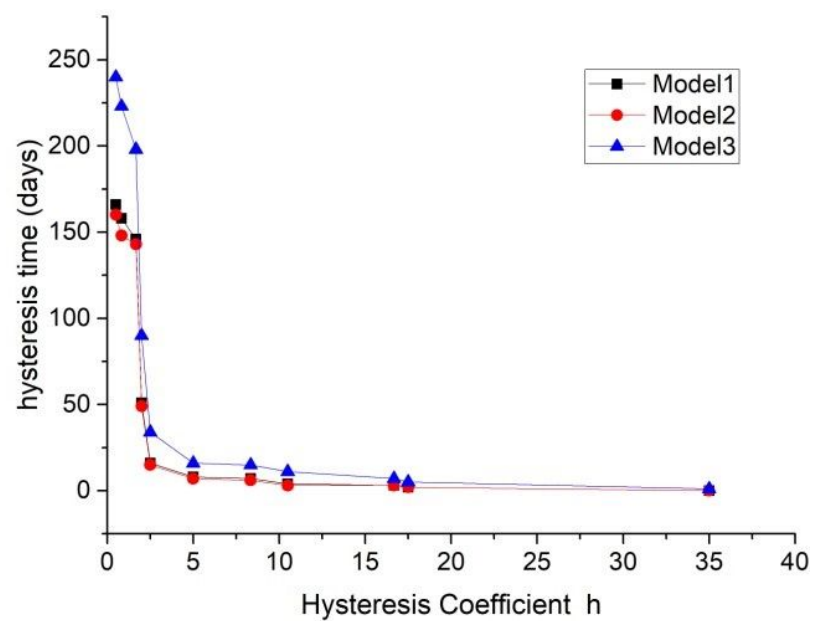

Figure 11: Variation curve of lag time with hysteresis coefficient

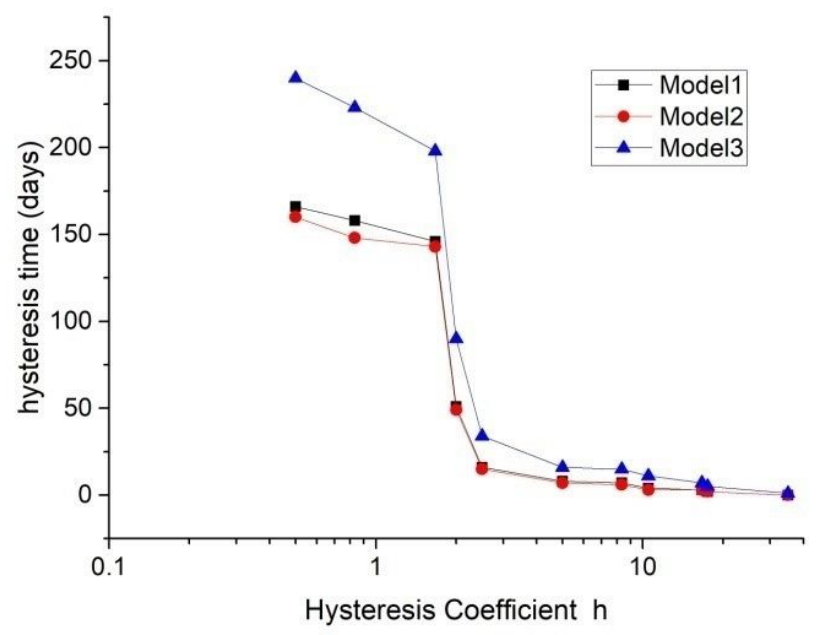

Figure 12: Logarithmic curve of lag time with hysteresis coefficient

\subsubsection{Change law of seepage field}

In the Three Gorges Reservoir Area, the seepage flow field of the wading landslide periodically changes due to the fluctuation of the reservoir water level. According to the different characteristics of the seepage curve of landslide bodies and the characteristics of the seepage field, it can be divided into two types: hysteretic type and synchronous type (Figure 13).

As stated in previous sections, if $h \geq 35$, lag time is effectively zero, indicating that seepage in landslides and water level fluctuations will be synchronous (Figures 13a and 13c). For values lower than this threshold, there will be a difference at the free field boundary between water level within the landslide and in the reservoir. When the reservoir water level is increasing, the water level within the landslide will follow a concave curve that will tend to reach the new height of the reservoir level, as shown by Figure 13b. On the contrary, if the reservoir water level is decreasing, the water-table in the landslide will follow a convex curve that will lag upwards from the new reservoir level, as shown in Figure 13d.

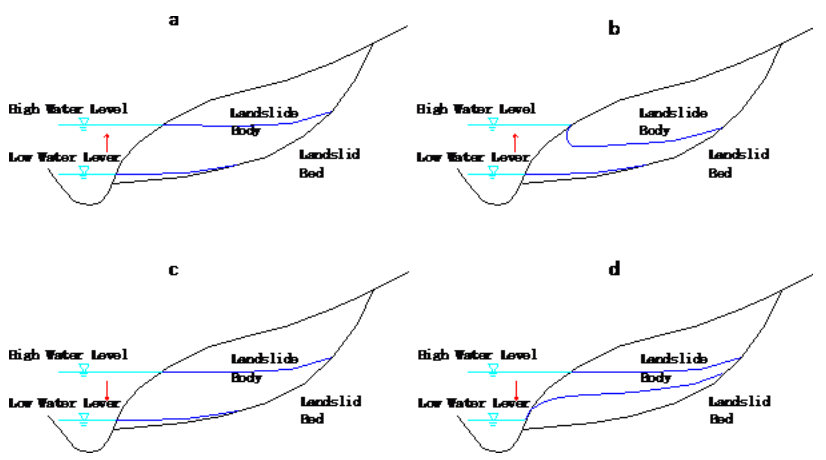

Figure 13: Change characteristics of seepage field under the rise and decline of reservoir water level.

(a) Synchronous type when water level rises, $h \geq 35$, (b) Hysteresis type when water level rises, $h<35$, (c) Synchronous type when water level declines, $h \geq 35$, (d) Hysteresis type when water level declines, $\mathrm{h}<35$

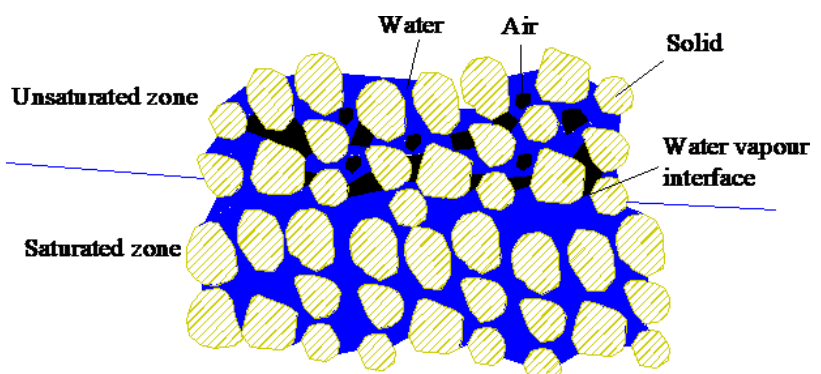

Figure 14: Mode of saturated and unsaturated soil-rock mixed structure

\section{Discussion}

It is widely assumed that the seepage flow of a landslide in a reservoir is synchronous with the water level change within it if the water permeability coefficient of the landslide is at least equal to the rate of change of water in the reservoir. We found that this is wrong. Lag time will become practically zero only if $h \geq 35$. In order to achieve this condition, the ratio between the water permeability coefficient and the rate of change of water level must be sizably 
larger than one. Moreover, it is also conditioned by length of the seepage path and the shape of the slope surface.

This is due to the behavior of soil at the boundary between saturated and unsaturated landslide material (Figure 14). When water level declines in the reservoir, suction is generated at the water vapor interface leading to the development of a drag action that slows free water descent. In contrast, when the water level increases in the reservoir, water flows into unsaturated areas that have air bubbles. These bubbles constrain the hydraulic cross section leading to a lower effective permeability. These trends have been verified by Sun and his collaborators [34]. They set up a real-time pore-pressure monitoring system in $\mathrm{Li}$ jiapo landslide in the Three Gorges Reservoir Area. Based on long-term and continuous monitoring data, the maximum observed seepage lag time was 10 days during falls in reservoir level. They reported a saturated permeability coefficient of $1.955 \mathrm{~m} / \mathrm{d}$, a slope angle of $34^{\circ}$, and a hysteresis coefficient of 3.26. According to Table 9, the degree of hysteresis for the Lijiapo landslide is weak. According to Equation (2), its lag time can be estimated at 6 days. Thus, there is an agreement between our results and field collected data.

\section{Conclusions}

Slope failures of the banks of the Yangtze River is a concern in the Three Gorges Reservoir. Since 2003 at least eight landslides have deposited waste material directly into the river, which could compromise navigation and induce unexpected actions in the lake. Extensive research on these cases has shown a direct link between changes in reservoir level and slope creeping and eventual collapse. Albeit extensive research has been done, there are still gaps in knowledge that must be addressed. Results from our study show that banks of the reservoir are expected to experience hysteresis effects, implying that changes in water table levels within soil landslides can be delayed for at least one day after the reservoir water level changes, even if the hysteresis parameter is smaller than 35 . Furthermore, we found that the general idea that hysteresis is a minor factor if the change of reservoir level is less than the permeability of the slope is wrong. Our results show that a hysteresis coefficient of 35 can be used approximately as the limit value of the seepage to discern between hysteretic and synchronous behaviors. At least $90 \%$ of landslides in the Three Gorges Reservoir area showcase hysteresis. Hysteresis coefficients of 1.67 and 2.5 were proposed as the threshold values to distinguish between the strong, medium, and weak hysteresis of the seepage flow in the Three Gorges Reservoir Area.

We calibrated the behavior of partially saturated materials within these soil landslides using the threeparameter Fredlund-Xing model. We found that the a and $\mathrm{m}$ parameters are positively correlated with gravel particle size, dry density, and the plasticity index of soil particles. These variables are negatively correlated with gravel content. The $\mathrm{n}$ parameter shows completely opposite trends. This is explained by the complex interactions between soil, water, and air in the seepage boundary.

This research provides valuable insight into the assessment of slope stability in the margins of large man-made lakes. It shows how bodies that are initially considered to be insensitive to hydrological hysteresis can be extensively affected by it instead. Furthermore, it presents an efficient way to assess their behavior; thus, contributing to improving the safety and smooth operation of water reservoirs worldwide.

Acknowledgements This work was financially supported by the Key Scientific Project of TGR (No. 000121 2015C C60 005), the National Natural Science Funds for Creative Research Groups of China (No. 41521002), and the Key Project of Applied Basic Research of Sichuan Province (No. 19YYJC1481). We extend our thanks to the Monitoring Center of the Three Gorges for providing the landslide data. The authors wish to thank the anonymous referees for their helpful suggestions and constructive comments, which have contributed greatly to improving the quality of the manuscript.

Author Contributions: Minggao Tang conceived and designed the study; He Yang performed the study and wrote the paper; Qiang Xu provided some guidance on the study; Zhengfeng Gong and Yangjian Cao and Huajin Li collected the data; Xiaolin Fu provided some basic data; AndresAlonso Rodriguez revised extensively the latest version of the manuscript and provided background information about geotechnical engineering.

\section{References}

[1] Luo X.Q., Wang F.W., Zhang Z.H., Che A.L., Establishing a monitoring network for an impoundment-induced landslide in Three Gorges Reservoir Area, China. Landslides, 2009, 6: 27-37, doi.org/10.1007/s10346-008-0140-5

[2] Jiao Y. Y., Song L., Tang H. M., Li Y. A., Material weakening of slip zone soils induced by water level fluctuation in the ancient landslides of Three Gorges Reservoir. Advances in Materials Science 
and Engineering, 2014: 9, doi.org/10.1155/2014/202340

[3] Yin Y.P., Huang B.L., Wang W.P., Wei Y.J., Ma X.H., Ma F., et al., Reservoir-induced landslides and risk control in Three Gorges Project on Yangtze River, China. Journal of Rock Mechanics and Geotechnical Engineering, 2016, 8 (5): 577-595, doi.org/10.1016/j.jrmge.2016.08.001

[4] Zhao N.H, Hu B., Yi Q.L., Yao W.M., Ma C., The coupling effect of rainfall and reservoir water level decline on the Baijiabao landslide in the Three Gorges Reservoir Area, China. Geofluids, 2017: 3724867, doi.org/10.1155/2017/3724867

[5] Zhou C., Yin K.L., Cao Y., Ahmed B., Application of time series analysis and PSO-SVM model in predicting the Bazimen landslide in the Three Gorges Reservoir, China. Engineering Geology, 2016, 204: 108-120, doi.org/10.1016/j.enggeo.2016.02.009

[6] Wang S.T., Liu H.C., Zhang Z.Y., Huang R.Q., Xu M., Shang Y.Q., et al., Study on interaction and environmental effects of water rocks in large water area. Journal of Geological Hazards and Environment Preservation, 1997, 8(1): 69-89 (in Chinese with English summary)

[7] Xu Q., Huang X.B., The manual of landslide hazard prediction and early warning in the Three Gorges Reservoir. Geology Press, Beijing, 2014 (in Chinese with English summary)

[8] Xiao S.R., Hu Z.Y., Lu S.S., Ming C.T., Chen D.Q., Classification of reservoir triggered landslides in Three Gorges Reservoir Area. Journal of Yangtze River Scientific Research Institute, 2013, 11: 39-44 (in Chinese with English summary)

[9] Liu W.P., Zhang L.M., Zheng Y.R., Li X., Investigation of shear strength and permeability parameters for landslide soils in the Chongqing section of the Three Gorge Reservoir Area. Chinese Journal of Underground Space and Engineering, 2009, 5 (01): 45 49 (in Chinese with English summary)

[10] Jian W.X., Xu Q., Wu H., Tong L.Y., Study of unsaturated hydraulic parameters of Huangtupo landslide in Three Gorges reservoir area. Rock and Soil Mechanics, 2014, 12: 3517-3522 (in Chinese with English summary)

[11] Ding S.L., Zuo C.Q., Liu D.G., Li L.S., Chen J.P., Soil-water characteristics of unsaturated residual soil and estimation of matric suction. Journal of Yangtze River Scientific Research Institute, 2016, 03: 98-103 (in Chinese with English summary)

[12] Tang M.G., Xu Q., Huang R.Q., Site monitoring of suction and temporary pore water pressure in an ancient landslide in the Three Gorges reservoir area, China. Environmental Earth Sciences, 2015, 73: 5601-5609, doi.org/10.1007/s12665-0143814-4

[13] Yang F., Research on effect of increasing the daily drop rate of the Three Gorges Reservoir Level on Remedied Landslides. Master thesis, Chengdu University of Technology, China, 2015

[14] Ren J.Q., The permeability of old landslide of various types of formations and the impact of water level fluctuations on its stability in the Three Gorges Reservoir Area. Master thesis, Chengdu University of Technology, China, 2016

[15] Sun G.H., Yang Y.T., Cheng S.G., Zheng H., Phreatic line calculation and stability analysis of slopes under the combined effect of reservoir water level fluctuations and rainfall, Canadian Geotechnical Journal, 2017, 54(5): 631-645, doi.org/10.1139/cgj-2016-0315

[16] Huang F.M., Luo X.Y., Liu W.P., Stability analysis of hydrodynamic pressure landslides with different permeability coefficients affected by Reservoir Water Level Fluctuations and Rain- storms. Water, 2017, 9(7): 450, doi.org/10.3390/w9070450

[17] Yi W., Meng Z.P., Yi Q.L., Theory and method of landslide stability prediction in the Three Gorges Reservoir Area. Science Press, Beijing, 2011

[18] Yi Q.L., Yi W., Shang M., Affecting factors of deformation of a certain landslide in the Three Gorges Reservoir Area. Soil and Water Conservation in China, 2009 (07): 32-34+64 (in Chinese with English summary)

[19] Li S.L., Xu Q., Tang M.G., Qian L.J., Ren J.Q., Response patterns of old landslides with different slip-surface shapes triggered by fluctuation of reservoir water level. Journal of Engineering Geology, 2017, 25 (03): 841-852 (in Chinese with English summary)

[20] Xu Q., Tang M.G., Yin K.L., Zhang G.D., Wen B.P., Pan W., et al., General report on the investigation and evaluation of the influence of daily water level decline of the Three Gorges Reservoir on geological hazard prevention and control projects in the reservoir area. China Geological Environment Monitoring Institute, Beijing, 2015

[21] Ju Z.B., Feng H., Shen L., Gao Y.J., Liu J.T., Li Z.J., et al., Code of water injection test for water resources and hydropower engineering (SL345-2007). China Water \& Power Press, Beijing, 2007

[22] China Geological Survey., Handbook of Hydrogeology (Second Edition). Geologic Press, Beijing, 2012

[23] Xu Y.F., Dong P., Fractal models for the soil-water characteristics of unsaturated soils. Rock and Soil Mechanics, 2002, 04: 400405 (in Chinese with English summary)

[24] Wang W.C., Xu J., Effects of current suction ratio and recent suction history on small-strain behaviour of an unsaturated soil. Canadian Geothecnical Journal, 2012, 49 (2): 226-243

[25] Peng Z.Y., Shi H.L., Lin Z.W., Analysis on the test operation error of volume pressure plate instrument. Safety and Environmental Engineering, 2011, 05: 119-122 (in Chinese with English summary)

[26] Fredlund D.G., Xing A., Equations for the soil-water charactertistic curve. Canadian Geotechnical Journal, 1994, 31: 521-532, doi.org/10.1139/t94-061

[27] Fredlund D.G., Xing A., Huang S., Predicting the permeability function for unsaturated soils using the soil-water characteristic curve. Canadian Geo-technical Journal, 1994, (31): 533-546, doi.org/10.1139/t94-062

[28] Li Z.Q., Hu R.L., Wang L.C., Li Z.X., Study on SWCC of unsaturated expansive soil. Rock and Soil Mechanics, 2006, 05: 730-734 (in Chinese with English summary)

[29] Li Z.Q., Li T., Hu R.L., Property of soil-water characteristic curve for unsaturated soil. China Journal of Highway and Transport, 2007, 03: 23-28 (in Chinese with English summary)

[30] Qi G.Q., Huang R.Q., An universal mathematical model of soilwater characteristic curve. Journal of Engineering Geology, 2004, 02: 182-186 (in Chinese with English summary)

[31] Liu X.M., Zhao H.L., Wang L.J., Experimental study on soil-water character of unsaturated powdery clay. Underground Space, 2001, S1:375-378+385-586 (in Chinese with English summary)

[32] Lu N., William J.L., Unsaturated soil mechanics. John Wiley\&Sons, Inc. Press, Hoboken, 2004

[33] Li H.J., Xu Q., He Y.S., Deng J.H., Prediction of landslide displacement with an ensemble-based extreme learning machine and copula models. Landslides, 2018, 15: 2047-2059, doi.org/10.1007/s10346-018-1020-2 
[34] Sun Y.J., Guo N., Pan S.T., Research on response relationship between seepage field in landslide and reservoir water level fluctuation: case of Lijiapo landslide in Three Gorges Reservoir area. Yangtze River, 2014, 45 (07): 66-69 (in Chinese with English summary) 